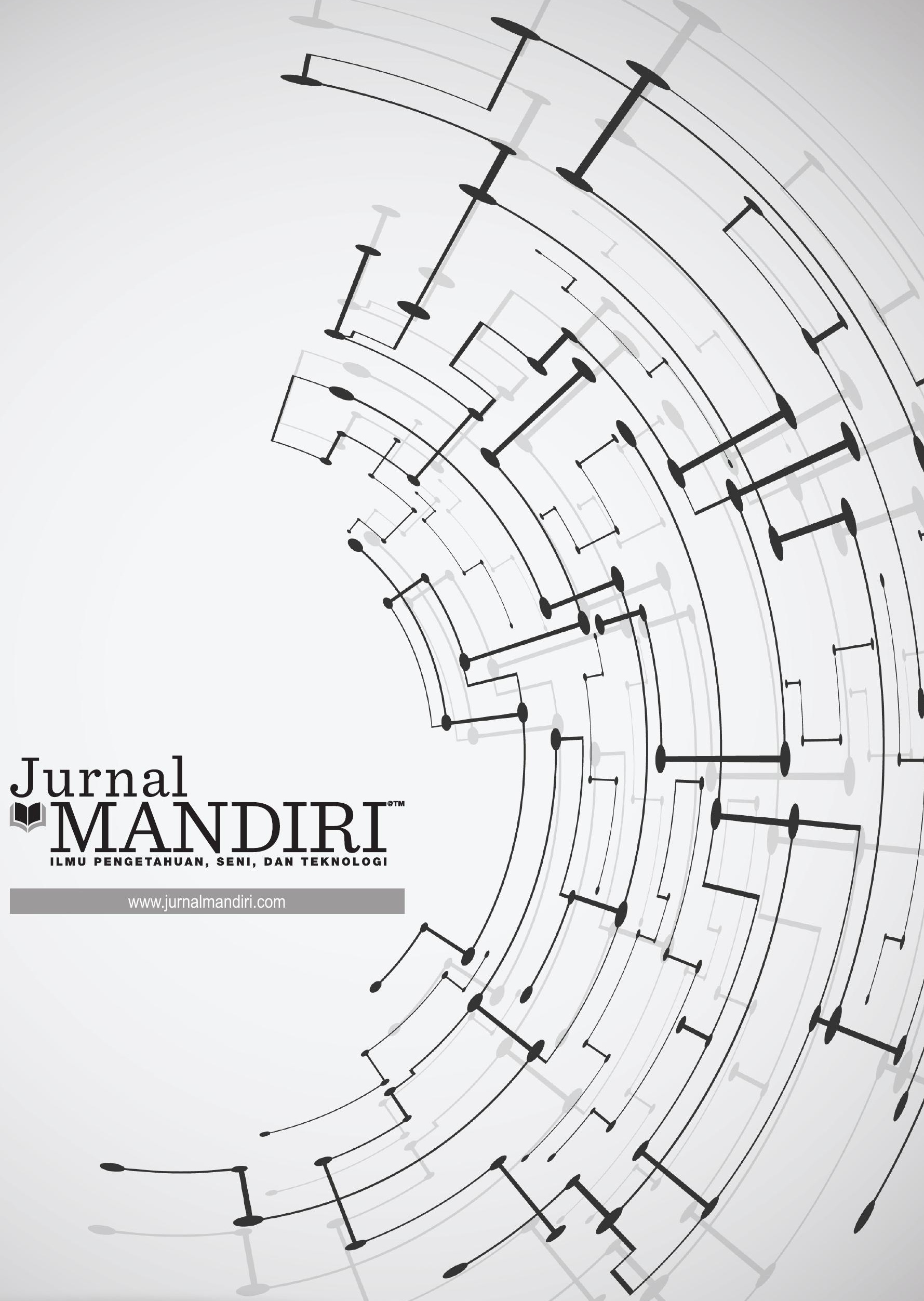


ISSN : 2580-3220, E-ISSN : 2580-4588

J. Mandiri., Vol. 3, No. 2, Desember 2019 (207 - 220)

(C)2018 Lembaga Kajian Demokrasi

dan Pemberdayaan Masyarakat (LKD-PM)

DOI : https://doi.org/10.33753/mandiri.v3i2.81

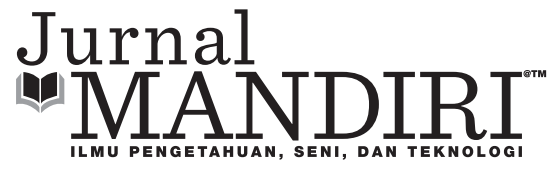

\title{
Strategi Bersaing PT. Adira Dinamika Multifinance, Tbk Cabang Baturaja
}

Firdaus

Fakultas Ekonomi, Universitas Pamulang

dosen01478@unpam.ac.id

\begin{abstract}
Abstrak
Penelitian ini bertujuan untuk mengetahui kondisi internal dan eksternal serta strategi bisnis yang sesuai dan cocok pada PT. Adira Finance, Tbk Cabang Baturaja kedepan sehingga mampu bersaing dan maju berkembang untuk masa yang akan datang. Penelitian dilakukan pada Adira Finance Cabang Baturaja. Jenis data yang digunakan adalah data primer dan sekunder melalui wawancara dan kuesioner kepada Pimpinan Cabangperusahaan, mitra bisnis dan responden sebanyak 100 orang. Metode analisis yang digunakan melalui tiga tahapan; tahapan pertama disebut dengan penginputan data menggunakan analisis matrik EFE dan analisis matrik IFE dengan total skor masing-masing 3,25\% dan 3,00\%; tahapan kedua mencocokkan data menggunakan analisis SWOT dan IE Matrik Internal Eksternal dimana adira berada pada kuadran I yaitu posisi tumbuh dan membangun (growth and built) dengan pemilihan strategi alternatif (strategi yang intensif); dan tahap ketiga tahap keputusan menggunakan analisis QSPM dengan prioritas strategi (penetrasi pasar).
\end{abstract}

Kata Kunci : Matriks EFE, Matrik IFE, SWOT, Matrik IE, dan QSPM

\section{Abstract}

The study was conducted at Adira Finance Baturaja Branch. Types of data used are primary and secondary data that are through interviews and questioners to Chairman Branch, business partners and the respondents as many as 100 people. The method of analysis used through three stages; the first stages, the input stage, using matrix analysis EFE and IFE matrix analysis with total score of each were 3,25\% and 3,00\%; the second stage, the matching stage, using SWOT analysis and IE Matrix Internal External where Adira was on quadran I that position to growth and built with the selection of alternative strategy is an intensive strategy; the third stage, decision stage, using analysis QSPM with priority strategy is market penetration.

Keywords : Matrix EFE, Matrix IFE, SWOT, Matrix IE, and QSPM

\section{PENDAHULUAN}

Dalam menyikapi tingkat persaingan yang semakin tajam, penting perusahaan untuk mampu merencanakan, memformulasikan, kontrol dan evaluasi atas setiap kebijakan strategi yang diambil dengan tujuan mampu menciptakan keunggulan bersaing perusahaan dalam industri. Adapun refleksi dari meningkatnya persaingan pada industri ini adalah semakin bertambahnya jumlah perusahaan pada masing-masing yang menjadi sasaran geografis perusahaan. Semakin tingginya tingkat persaingan yang semakin tajam akan berdampak pada trend pertumbuhan dan penurunan profitabilitas yang akan diterima perusahaan dimasa akan datang. Dengan demikian hal ini merupakan interpretasi semakin tingginya tingkat persaingan pada industri ini memberikan dampak terhadap bargaining power pada pihak 
konsumen dalam memilih dan berpindah dari perusahaan satu ke perusahaan lainnya yang dirasakan paling baik atas manfaat yang akan dirasakan ketika memutuskan menggunakan jasa pembiayaan tersebut.

Salah satu strategi yang dapat digunakan suatu perusahaan dalam posisi persaingan yang semakin tajam adalah strategi bersaing. Strategi bersaing adalah langkah-langkah strategis yang terencana maupun tidak terencana untuk dapat memiliki keunggulan bersaing sehingga dapat menarik perhatian konsumen, memperkuat posisi dalam pasar, dan bertahan terhadap tekanan persaingan (Hariadi, 2005). Sedangkan Porter (2001) mengatakan bahwa strategi bersaing adalah mengembangkan rencana mengenai bagaimana bisnis akan bersaing, apa yang seharusnya menjadi tujuannya dan kebijakan apa yang diperlukan untuk mencapai tujuan tersebut.

Strategi bersaing bagi perusahaan adalah untuk memperoleh keunggulan bersaing dengan menawarkan nilai pelanggan yang unggul. Tidak ada satu strategi yang baik untuk semua perusahaan. Setiap perusahaan harus menemukan apa yang paling masuk akal pada kedudukannya di industri bersangkutan dan sasaran, kesempatan dan sumber dayanya. Bahkan dalam satu perusahaan pun, strategi yang berbeda mungkin dibutuhkan untuk bisnis atau produk yang berbeda.

Dalam menentukan strategi yang tepat untuk bersaing, perusahaan dapat menggunakan analisis IFAS, EFAS dan QSPM. Berdasarkan analisis IFAS, perusahaan dapat menentukan faktor strategi internal yaitu kekuatan dan kelemahan. Berdasarkan analisis EFAS suatu perusahaan dapat menentukan faktor strategis eksternal, yaitu peluang dan ancaman. Sedangkan berdasarkan analisis QSPM suatu perusahaan dapat menentukan strategi mana yang paling utama untuk dilaksanakan untuk bersaing dengan perusahaan sejenis.

Industri otomotif merupakan sektor bisnis yang memiliki karakteristik tingkat persaingan yang cukup menarik. Hal ini terlihat dari fluktuasi perkembangan jumlah perusahaan pembiayaan yang ikut semakin banyak turut memberikan persaingan pada industri ini. Kondisi ini memiliki interpretasi ekspektasi perusahaan yang bergerak pada industri pembiayaan memperlihatkan dalam jangka waktu tertentu ekspektasi pasar untuk mengkonsumsi mobil bekas masih tetap memiliki potensi untuk dikembangkan.

Seiring dengan meningkatnya tingkat pembelian masyarakat terhadap mobil melalui lembaga pembiayaan, maka timbul persaingan perusahaan yang bersaing dalam industri lembaga pembiayaan tersebut. Seperti yang diungkapkan dalam republika online (2007) yang memperlihatkan sebanyak $90 \%$ aktifitas transaksi pembelian mobil di indonesia dilakukan dengan menggunakan jasa lembaga pembiayaan. Dengan demikian kondisi ini memperlihatkan lembaga pembiayaan merupakan sarana masyarakat dalam melakukan kredit mobil.

PT. Adira Dinamika Multifinance, Tbk merupakan salah satu perusahaan pembiayaan otomotif terbesar di Indonesia. Pada saat ini PT. Adira Dinamika Multifinance, Tbk khususnya Cabang Baturaja menghadapi permasalahan strategis yaitu makin meningkatkan persaingan dengan perusahaan sejenis. Hal ini tentu berdampak pada profitabilitas perusahaan bersangkutan. Sehingga diperlukan suatu strategi yang tepat agar perusahaan dapat bertahan atau memenangkan persaingan.

Manfaat dari penelitian ini adalah sebagai bahan referensi dan pertimbangan bagi pemilik dalam pengambilan keputusan yang strategik demi perkembangan bisnis PT. Adira Cabang Baturaja.

\section{METODE}

Jenis penelitian yang dilakukan ini berupa penelitian deskriptif eksploratif melalui pendekatan studi kasus (case study). Tujuan dari penelitian deskriptif ekploratif tersebut adalah untuk membuat gambaran secara sistematis dan akurat mengenai fakta, sifat, dan hubungan antar aspek yang diteliti baik secara kuantitatif ataupun kualitatif. Oleh karena itu penelitian dilakukan dalam upaya mengidentifikasi faktor lingkungan perusahaan baik internal maupun eksternal. 
Data primer, yaitu data yang diperoleh secara langsung dari narasumber, dan belum melalui proses pengolahan sebelumnya yang sesuai dengan objek yang diteliti, baik berupa data kuantitatif ataupun data kualitatif. Data ini berupa opini subjek (orang) secara individu maupun kelompok, hasil observasi terhadap benda (fisik), kejadian atau kegiatan objek yang diteliti, dimana diperoleh langsung dari sumbernya, diamati, dicatat dan juga melalui wawancara interview dengan pihak pimpinan PT. Adira Finance Baturaja, dan dealer-dealer yang dalam hal ini pimpinannya, yang menggunakan jasa PT. Adira Finance serta survei visual berupa tanggapan dan pendapat nasabah terhadap aktivitas operasi perusahaan.

Data sekunder, yaitu data yang telah diolah sebelumnya dan diperoleh dari sumber kedua yang masih berkaitan dengan objek penelitian yang dikumpulkan secara langsung maupun tidak langsung. Data sekunder dapat dikumpulkan dari beberapa sumber seperti buletin statistik, publikasi pemerintah, informasi yang dipublikasikan atau tidak dipublikasikan dari dalam atau luar perusahaan, data yang tersedia dari penelitian yang sebelumnya, studi kasus dan dokumen perpustakaan, data online, situs web dan internet.

Riset Perpustakaan, yaitu penelitian yang dilakukan dengan megumpulkan dan mempelajari teori-teori yang berhubungan dengan masalah yang dikaji yang dapat diperoleh dari literature bulletin, majalah-majalah, brosur dan bahan-bahan kuliah yang berhubungan dengan penulisan tesis ini.

Riset Lapangan; yaitu mengumpulkan langsung ke perusahaan yang bersangkutan dengan cara melakukan interview dengan pimpinan PT. Adira Finance dan pimpinan dealer yang menggunakan jasa Adira Baturaja.

Dalam penelitian ini juga digunakan data untuk pengamatan langsung di lapangan dalam bentuk quisuiner yang diperuntukkan kepada nasabah dan pimpinan dealer guna memperolah gambaran tentang taggapan konsumen terhadap aktifitas PT. Adira Cabang Baturaja dalam menjalankan usahanya.

Nasabah Adira sebagai responden untuk melihat kualitas pelayanan dan kepuasan pelanggan, yaitu pengambilan data primer dengan menggunakan kuisioner yang diambil secara acak sebanyak 100 konsumen. Umur responden konsumen yang diambil diatas 30 tahun sampai 60 tahun sebanyak 80 persen, 18 persen dibawah 30 tahun dan sebanyak 2 persen diatas 60 tahun. Dilihat dari jenis kelaminnya, 77 persen laki laki dan 13 persen perempuan. Sedangkan dari jenis pekerjaannya, 11 persen PNS, 15 persen Pegawai Swasta, sedangkan 74 persen wiraswasta. Dari tingkat pendidikannya 11 persen sarjana ( S1 dan D3) dan 89 persen SMA atau sederajat

Pimpinan PT. Adira Finance, Priyo Utomo selaku sumber utama yang memberikan gambaran mengenai kegiatan perusahaan. Dengan data ini akan diperoleh gambaran tentang strategi dan faktor yang menjadi pendukung kegiatan perusahaan. Priyo Utomo telah bekerja di Adira lebih 10 tahun, dan pernah juga memimpin Cabang di daerah lainnya selain di Sumbar.

Para rekanan Adira, yaitu pimpinan dealer untuk mendapatkan keys Success factor yang terdiri dari dua orang pimpinan dealer. Pengumpulan data dari pimpinan dealer dilakukan dengan menggunakan model komperatif dalam bentuk pembobotan. Fredy merupakan pimpinan dealer Sahabat Indah Motor. Karvino merupakan pimpinan dealer Galih Jaya Mobilindo. Penetapan jumlah responden untuk kajian ini dilakukan dengan metode tidak acak yaitu pemilihan sampel bertujuan (purpose sampling). Indrianto dan Suparno (1999) mengemukakan bahwa peneliti kemungkinan mempunyai tujuan atau target tertentu dalam memilih sampel ini, yaitu pemilihan sampel berdasarkan pertimbangan (judgement sampling) dan berdasarkan koata (quota sampling). Penelitian ini digunakan jenis judgement sampling di mana informasinya diperoleh dengan menggunakan pertimbangan tertentu (disesuaikan dengan tujuan atau masalah penelitian). Dalam penelitian ini sampel yang dipilih adalah pimpinan Adira dan pimpinan dealer yang bisa memberikan masukan buat penyelesaian penelitian ini. Elemen populasi yang dipilih sebagai sampel dibatasi pada elemenelemen yang dapat memberikan informasi ber- 
dasarkan pertimbangan. Faktor kepraktisan (kecepatan waktu dan biaya yang murah) merupakan pertimbangan pokok dalam metode pemilihan sampel secara tidak acak ini.

Data-data yang telah diidentifikasi kemudian diolah untuk dianalisis. Menurut David (2011), proses formulasi strategi perusahaan dilaksanakan dengan melalui 3 tahapan, dan dalam masingmasing tahapan tersebut terdapat beberapa tools, yang bisa digunakan sebagai alat ukur, dalam pengambilan keputusan, tahapan tersebut adalah:

\section{Tahap Pengumpulan Data (The Input Stage)}

Pada tahap ini digunakan analisis matriks EFE, matriks IFE. Kedua matriks ini bertugas menyimpulkan informasi dasar yang diperlukan perusahaan untuk merumuskan strategi.

\section{Analisis Matriks EFE}

Analisa terhadap faktor-faktor lingkungan eksternal perusahaan yang dapat berpengaruh baik secara langsung maupun tidak langsung, yaitu, faktor ekonomi, politik, sosial budaya, teknologi, demogradi dan ekologi. Dengan dilakukannya analisis EFE maka akan dilakukan analisa menyeluruh terhadap setiap faktor lingkungan eksternal yang berpengaruh bagi perusahaan. Merupakan analisa terhadap faktor-faktor lingkungan eksternal perusahaan yang dapat berpengaruh baik secara langsung maupun tidak langsung, yaitu : faktor ekonomi, politik, sosial budaya, teknologi, demografi, dan ekologi. Matriks EFE dapat dikembangkan dalam lima langkah (David. 2011)

1. Buatlah daftar key external factor (faktor utama yang mempunyai dampak penting pada kesuksesan atau kegagalan usaha) untuk aspek eksternal yang mencakup perihal peluang (opportunities) dan ancaman (threats) yang mempengaruhi perusahaan dan industrinya.

2. Tentukan bobot (weight) dari key external factor tadi dengan kisaran skala dari 0.0 (tidak penting) sampai 1.0 (terpenting) pada setiap faktor. Bobot yang diberikan pada suatu faktor menunjukkan kepentingan relatif dari setiap faktor dalam perusahaan. Jumlah seluruh bobot harus sebesar 1.0.
3. Beri rating (nilai) antara 1 sampai 4 bagi masing-masing faktor, baik itu peluang maupun ancaman, pemberian nilai bertujuan untuk mengetahui seberapa efektif strategi perusaan saat ini dalam mengantisipasi faktor-faktor yang ada, keterangan dari masingmasing nilai adalah:

4 = Sangat bagus (superior)

$3=$ diatas rata-rata (above average)

2 = Rata-rata (average)

$1=$ Dibawah rata rata (poor)

4. Kalikan antara bobot dan rating dari masingmasing faktor untuk mendapatkan total skor.

5. Jumlahkan semua skor untuk mendapatkan skor total keseluruhan bagi perusahaan. Skor keseluruhan dengan nilai 4.0 mengindikasikan bahwa perusahaan merespon dengan cara yang luar biasa terhadap peluang-peluang yang ada dan menghindari ancaman-ancaman di pasar industrinya. Sementara itu skor keseluruhan dengan nilai 1.0 menunjukkan bahwa perusahaan tidak memanfaatkan peluang-peluang yang ada atau tidak menghindari ancaman. Nilai rata-rata adalah 2,5 . Jika nilainya dibawah 2,5 menandakan bahwa secara eksternal perusahaan mengalami banyak ancaman, sedangkan nilai yang berada diatas 2,5 menunjukkan secara eksternal perusahaan memiliki banyak peluang.

\begin{tabular}{|l|c|c|c|}
\hline \multicolumn{4}{c|}{ Tabel 1. Matriks EFE } \\
\hline \multicolumn{1}{|c|}{ KEY EXTERNAL FACTOR } & WEIGHT & RATING & WEIGHTED SCORE \\
\hline $\begin{array}{l}\text { Peluang (Opportunity) } \\
\text { Isikan faktor-faktor peluang }\end{array}$ & & & \\
\hline $\begin{array}{l}\text { Ancaman (threat) } \\
\text { Isikan faktor-faktor ancaman }\end{array}$ & & & \\
\hline Total & 1.0 & & \\
\hline
\end{tabular}

\section{Analisis Matriks IFE}

Analisa bertujuan untuk mengevaluasi kekuatan dan kelemahan terbesar yang memiliki pengaruh secara langsung terhadap strategi perusahaan. Analisa ini dilakukan terhadap setiap faktor lingkungan internal yang berpengaruh terhadap perusahaan. Sama halnya dengan matriks EFE, matriks ini juga dapat dikembangkan dengan 5 langkah (David. 2011) 
1. Buatlah daftar key internal factor yang mencakup kekuatan (strength) dan kelemahan (weakness) yang mempengaruhi perusahaan dan industrinya.

2. Tentukan bobot (weight) dari key internal factor tadi dengan kisaran skala dari 0.0 (tidak penting) sampai 1.0 (terpenting) pada setiap faktor. Bobot yang diberikan pada suatu faktor menunjukkan kepentingan relatif dari setiap faktor dalam perusahaan. Jumlah seluruh bobot harus sebesar 1.0.

3. Beri rating (nilai) antara 1 sampai 4 bagi masing-masing faktor, baik itu kekuatan maupun kelemahan, dengan keterangan :

$4=$ kekuatan utama (major strength)

$3=$ kekuatan pendukung (minor strength)

$2=$ kelemahan pendukung (minor weakness)

$1=$ kelemahan utama (major weakness)

4. Kalikan antara bobot dan rating dari masingmasing faktor untuk mendapatkan total skor.

5. Jumlahkan semua skor untuk mendapatkan skor total keseluruhan bagi perusahaan. Skor berkisar antara 1.0 sampai 4.0, dengan 2.5 sebagai skor rata-rata. Perusahaan yang memiliki skor keseluruhan dibawah 2.5 berarti lemah secara internal, dan kuat secara internal jika skor nya lebih dari 2.5 .

\begin{tabular}{l|c|c|c|}
\hline \multicolumn{4}{c|}{ Tabel 2. Matriks IFE } \\
\hline \multicolumn{1}{c|}{ KEY EXTERNAL FACTOR } & WEIGHT & RATING & WEIGHTED SCORE \\
\hline $\begin{array}{l}\text { Kekuatan (Strength) } \\
\text { Isikan faktor-faktor kekuatan }\end{array}$ & & & \\
\hline $\begin{array}{l}\text { Kelemahan (Weakness) } \\
\text { Isikan faktor-faktor kelemahan }\end{array}$ & & & \\
\hline Total & 1.0 & & \\
\hline
\end{tabular}

\section{Tahap Mencocokan (The Matching Stage)}

\section{Analisa SWOT}

Setelah melalui tahap pengumpulan data, maka proses formulasi berlanjut ke tahap berikutnya yaitu tahap mencocokkan (matching stage). Hasil analisa IFE dan EFE akan diolah ke dalam matriks TOWS, pada tahap ini berfokus pada pembuatan strategi-strategi alternatif yang dapat dilaksanakan melalui penggabungan faktor internal dan eksternal, yang akan menghasilkan SO, WO, ST, dan WT.

Menurut Fred R. David (2011) ada delapan tahapan penentuan strategi yang dibangun melalui matrik TOWS, yaitu :

1. Buat daftar peluang eksternal perusahaan.

2. Buat daftar ancaman eksternal perusahaan.

3. Buat daftar kekuatan kunci internal perusahaan.

4. Buat daftar kelemahan kunci internal perusahaan.

5. Cocokkan kekuatan-kekuatan internal dengan peluang-peluang eksternal dan catat hasilnya dalam sel strategi SO.

6. Cocokkan kelemahan-kelemahan internal dengan peluang-peluang eksternal dan catat hasilnya dalam sel strategi WO.

7. Cocokkan kekuatan-kekuatan internal dengan ancaman-ancaman eksternal dan catat hasilnya dalam sel strategi ST.

8. Cocokkan kelemahan-kelemahan internal dengan ancaman-ancaman eksternal dan catat hasilnya dalam sel strategi WT.

\begin{tabular}{|l|c|c|}
\hline \multicolumn{3}{|c|}{ Tabel 3. Matriks TOWS } \\
\hline & $\begin{array}{c}\text { STRENGTH } \\
\text { (KEKUATAN) }\end{array}$ & $\begin{array}{c}\text { WEAKNESS } \\
\text { (KELEMAHAN) }\end{array}$ \\
\hline $\begin{array}{l}\text { Catat kekuatan } \\
\text { internal yang ada }\end{array}$ & $\begin{array}{c}\text { Catat kelemahan } \\
\text { internal yang ada }\end{array}$ \\
\hline $\begin{array}{l}\text { Opportunity (kesempatan) } \\
\text { Catat peluang eksternal yang ada }\end{array}$ & SO & WO \\
\hline $\begin{array}{l}\text { Threat (ancaman) } \\
\text { Catat ancaman eksternal yang ada }\end{array}$ & ST & WT \\
\hline
\end{tabular}

Matriks Internal Eksternal (IE Matrix)

IE Matrix terdiri dari dua dimensi yaitu skor total dari IFE Matrix pada sumbu X dan skor total dari EFE Matrix pada sumbu Y. Ingat kembali bahwa suatu organisasi harus membuat Matriks IFE dan Matriks EFE dalam kaitannya dengan organisasi. Skor bobot total yang diperoleh memungkinkan susunan Matriks IE dalam suatu perusahaan. Pada sumbu x dari Matriks IE, skor bobot IFE total 1,0 sampai 1,99 menunjukkan posisi internal yang lemah; skor 2,0 sampai 2,99 dianggap sedang; dan skor 3,0 sampai 4,0 adalah kuat. Serupa dengannya, pada sumbu y, skor bobot EFE total 1,0 sampai 1,99 dipandang rendah; skor 2,0 sampai 2,99 dianggap sedang; dan skor 3,0 hingga 4,0 adalah tinggi (Umar, 1999:182).

Menurut David (2009:345), Matriks IE dapat dibagi menjadi tiga bagian besar yang mem- 
punyai implikasi strategi yang berbeda-beda. Pertama, ketentuan untuk divisi-divisi yang masuk dalam sel I, II, atau IV dapat digambarkan sebagai tumbuh dan membangun (grow and built). Strategi yang intensif (penetrasi pasar, pengembangan pasar, dan pengembangan produk) atau integratif (integrasi ke belakang, integrasi ke depan, dan integrasi horizontal) bisa menjadi yang paling tepat bagi divisi-divisi ini. Kedua, divisi-divisi yang masuk dalam sel III, V, atau VII dapat ditangani dengan baik melalui strategi menjaga dan mempertahankan (hold and maintain); penetrasi pasar dan pengembangan produk adalah dua strategi yang paling banyak digunakan dalam jenis divisi ini. Ketiga, ketentuan umum untuk divisi yang masuk dalam sel VI, VIII, atau IX adalah panen atau divestasi (harvest or divest).

\section{Tahap Keputusan (The Decision Stage)}

Setelah melalui tahap pencocokan dengan matriks TOWS, maka akan diperoleh 4 alternatif strategi yang bisa digunakan. Namun Sebelum digunakan strategi tersebut haruslah benar-benar sesuai dengan keadaan perusahaan saat ini, karena itulah perlu dilakukan proses terakhir yaitu proses keputusan dengan mengevaluasi kembali secara objektif dengan menggunakan Quantitative Strategic Planning Matrix atau matriks QSPM. Ada enam langkah dalam pembuatan metriks QSPM menurut David (2012:355) :

1. Menuliskan daftar peluang, ancaman, kekuatan dan kelemahan, yang diperoleh dari matriks EFE dan IFE.

2. Beri weight pada masing-masing key internal factor dan key external factor. Bobot ini sama dengan yang ada di matriks IFE dan EFE.

3. Tuliskan strategi alternatif yang akan dievaluasi.

4. Apabila faktor yang bersangkutan ada pengaruhnya terhadap strategi yang sedang dipertimbangkan, berikan nilai Attractiveness Score (AS) yang dimulai dari 1 (tidak menarik), 2 (agak menarik), 3 (menarik), dan 4 (sangat menarik). Sedangkan apabila tidak ada pengaruhnya terhadap strategi alternatif yang sedang dipertimbangkan, jangan beri- kan nilai AS.

5. Hitung Total Attractiveness Score (TAS). TAS didapat dari perkalian weight (tahap2) dengan AS (tahap 4) pada masing-masing baris. TAS menunjukkan relative attractiveness dari masing-masing alternatif strategi.

6. Hitung Sum Total Attractive Score. Jumlahkan semua total attractiveness score pada masingmasing kolom QSPM. Dari beberapa nilai TAS yang didapat, nilai TAS dari alternatif strategi yang tertinggilah yang menunjukkan bahwa strategi tersebut yang menjadi prioritas. Hal ini berlaku untuk selanjutnya. Dalam pemberian rating haruslah perbaris bukan perkolom untuk penyelesaiannya, dan hindari nilai score yang double.
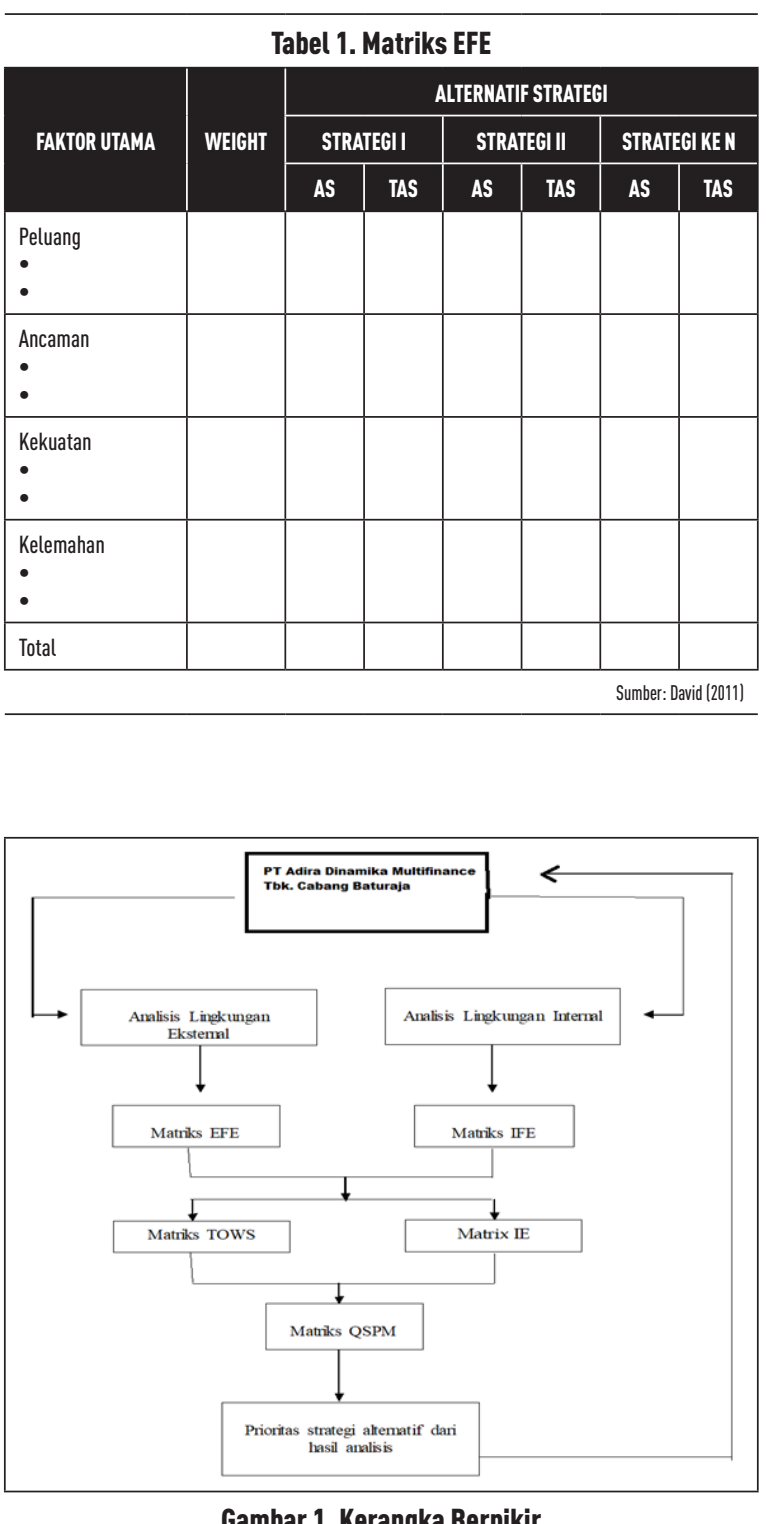

Gambar 1. Kerangka Berpikir 


\section{HASIL dan PEMBAHASAN}

Tahap analisis merupakan suatu proses pengolahan data guna mengindentifikasi strategi-strategi yang telah diterapkan PT. Adira Finance dalam menjalankan usahanya saat ini serta menentukan bentuk strategi yang dapat diterapkannya guna meningkatkan pengembangan usaha ke depan.

Pada bab ini akan dan dijelaskan visi dan misi dan strategi perusahaan dalam upaya mengendalikan bisnis pembiayaan yang akan datang. Visi, misi, dan strategi perusahaan ini merupakan kegiatan atau aplikasi serta tujuan masa depan yang akan dicapai perusahaan baik di mata pelanggan, dealer, karyawan, dan pemegang saham.

Visi Perusahaan : Menjadi perusahaan pembiayaan kelas dunia

- Membangun market presence yang signifikan (merk, pangsa pasar, jaringan usaha, produk/ pelayanan)

- Menjalankan proses operational yang terstandarisasi dan excellent.

- Menciptakan kontribusi nilai (value) yang berkelanjutan bagi para pemangku kepentingan.

Misi Perusahaan :

- Menyediakan produk dan pelayanan yang terdiversifikasi melalui beragam saluran distribusi.

- Melaksanakan operational excellence dan manajemen risiko yang baik.

- Menyediakan tempat bekerja terbaik bagi karyawan.

- Memampukan komunitas untuk mengalami kesejahteraan.

Pada bagian ini akan dijelaskan mengenai temuan-temuan yang penulis dapat dalam penelitian yaitu berupa proses dalam formulasi strategi yang terdiri dari tahap pengumpulan data, tahap mencocokkan dan tahap pemilihan strategi.

\section{Tahap Pengumpulan Data (The Input Stage)}

Dalam tahap pengumpulan data ini, penulis mengumpulkan beberapa sumber yang dapat dijadikan dasar dalam pemilihan key factor external maupun internal peruhasaaan, setelah dilakukan proses identifikasikasi lingkungan pada PT. Adira Multifinance Cabang Baturaja, maka didapatlah beberapa faktor kunci eksternal yang berupa ancaman terhadap perusahaan serta kesempatankesempatan yang bisa diraih dan dimanfaatkan oleh perusahaan.

Selain itu juga ditemukan faktor kunci internal yang berupa kekuatan yang dimiliki perusahan untuk mengantisipasi (overcome) kelemahankelemahan perusahaan. Kedua faktor internal dan eksternal yang telah tersebut, kemuadian akan di susun kedalam bentuk matriks EFE dan IFE untuk melihat bagaimana kondisi keseluruhan perusahaan baik itu secara eksternal, maupun secara internal

\section{Analisis Faktor Kunci Eksternal}

Faktor-faktor yang terdapat dalam analisis ini digunakan untuk menyusun matriks EFE, yang terdiri dari peluang (opportunity) dan ancaman (threat) yang dihadapi perusahaan, setelah dilakukan proses identifikasi maka peluang dan ancaman yang dimikili oleh PT. Adira Multifinance Cabang Baturaja adalah:

\section{Peluang}

1. Jumlah merk mobil dan dealer mobil hampir merata

Meningkatnya jumlah penjualan mobil di area cover Baturaja dapat dilihat dari Polisi Register (POLREG) tahun 2010 sampai 2013, terlihat adanya peningkatan penjualan pada tahun 2011 sebanyak 11.583 unit atau naik $66 \%$ dari tahun sebelumnya, dan di tahun 2012 sebanyak 13.314 unit atau naik 15\% dari tahun 2010. Peningkatan penjualan tersebut dikarenakan jumlah dealer authorized mobil merata (sumber; data Polreg 2010/2014). Secara keseluruhan, pasar mobil mengandalkan kerjasama antara 3 aspek, yaitu perusahaan leasing (Adira), pelanggan, dan dealer. Dengan meratanya jumlah merk dan dealer di daerah baturaja tentunya merupakan peluang yang bagus bagi PT. Adira Multifinanca CabangBaturaja.

2. Adanya dealer mobil bekas yg belum tergarap Adira Finance Baturaja sebagai salah satu 
perusahaan pembiyaan di Baturaja telah membuka kerja sama dengan 26 PKS; 14 adalah mobil baru dan 12 mobil bekas. Sementara total dealer bekas yang berada pada cover area Baturaja adalah 22 dealer. Dalam hal ini, untuk mempertahankan menjalankan bisnisnya, penting bagi PT. Adira Multifinance Cabang Baturaja untuk memikili koneksi yang baik dengan pihak dealer, dan dengan masih ada 10 dealer yang belum digarap, memberikan peluang bagi PT. Adira dalam pertambahan dealer langganan.

3. Permintaan masyarakat yang cukup tinggi terhadap kredit kendaraan

Pemberian kredit untuk pembelian kendaraan, memberikan respon yang positif dari masyarakat, dengan tingginya minat masyarakat terhadap kredit kendaraan, tentunya akan memberikan kesempatan pasar yang lebih besar bagi PT. Adira Multifinance Cabang Baturaja, sebagaimana yang diungkap media bahwa 90\% pembelian kendaraan adalah melalui kredit (sumber; Republika online, 2007, data Polreg)

4. Pertumbuhan penduduk, sektor niaga yang tinggi

Semakin meningkatnya pertumbuhan penduduk dan berkembangnya sektor niaga, maka semakin besar peluang PT. Adira Multifinance Cabang Baturaja untuk memperoleh konsumen baru. Seiring bertambahnya penduduk akan menyebabkan bertambahnya permintaan kredit kendaraan, dan sektor niaga yang meningkat juga akan diikuti dengan bertambahnya daya beli masyarakat.

5. Pelanggan yang terdiri hampir seluruh lapisan masyarakat

Kredit kendaraan sekarang bukan lagi hanya menjadi milik golongan masyarakat tertentu. Pelanggan dari PT. Adira Multifinance terdiri dari hampir seluruh masyarakat. Tentunya ini akan memberikan peluang yang bagus bagi perusahaan.

\section{Ancaman}

1. Harga komoditi pertanian belum stabil
Cover area Cabang Baturaja yang terdiri dari 7 Kabupaten yaitu Kabupaten Oku Induk, Oku Selatan, Oku Timur, Muara enim, Lahat dan Pagar Alam dengan luas 16348,09 km² dengan komuditi pertanian yang beragam yaitu Karet, sawit, kopi dan sawah. Dengan luas karet 393.687 Ha, sawit 826.135 Ha. Dari 2 komiditi diatas memperlihatkan $74 \%$ dari wilayah Baturaja adalah perkebunan, hal ini sangat berpengaruh terhadap perekonomian di wilayah Baturaja jika terjadi penurunan harga yang sangat signifikan; harga karet yang hanya Rp5.900 di tingkat petani yang biasanya dapat menempuh di kisaran Rp.1606 (Republika online; 2013). Perekonomian yang tidak stabil tentunya menyebabkan menurunnya pendapatan dari masyarakat, dan hal ini tentunya juga akan mengancam bisnis dari PT. Adira Multifinance Cabang Baturaja mengingat pelanggan dari perusahaan ini terdiri dari hampir seluruh lapisan masyarakat.

2. Adanya peraturan tentang DP (down payment)

Bisnis leasing yang sangat berhubungan dengan uang setor yang akan dikeluarkan pelanggan, tentunya akan sangat sensitif terhadap regulasi pemerintah. Dalam hal ini kebijakan yang ditetapkan oleh Bank Indonesia dan Kementrian Keuangan akan sangat berpengaruh terhadap bisnis PT. Adira Multifinance Cabang Baturaja. (sumber: PP No.14/33/DPbs perihal down payment bagi kredit rumah dan kendaraan bermotor)

3. Asumsi DP rendah menguntungkan masyarakat

DP atau down payment merupakan salah satu syarat penting dalam pengajuan kredit kendaraan. Semakin banyak DP yang dibayarkan, maka masa kredit akan semakin pendek, dan semakin sedikit DP yang dibayarkan tentunya akan membuat masa angsuran menjadi lama, dan anggapan masyarakat yang mengganggap DP rendah menguntungkan akan membahayakan bagi PT. Adira Multifinance CabangBaturaja, karena masa angsuran yang lama merupakan kredit 
yang resiko yang tinggi bagi perusahaan.

4. Afiliasi Bank dengan bunga murah menjadi ancaman

Industri kredit kendaraan merupakan industri yang sangat menguntungkan, dan pada industri yang sangat menguntungkan akan membawa perusahaan-perusahaan lain untuk ikut serta dalam industri tersebut. Luasnya pangsa pasar yang ada dan tingginya tingkat keuntungan yang diberikan telah membawa bang-bank yang telah mapan, untuk ikut serta dalam industri ini, dan tentunya bank-bank tersebut lebih mampu menawarkan tingkat bunga dan DP yang murah. Hal ini dapat dilihat dari beberapa afiliasi bank yang memberikan pinjaman bunga sebesar 5 sampai 7\% flat kepada nasabah (sumber: carikredit.com; 2012)

5. Adanya dealer nakal

Adanya dealer-dealer bekas yang menjual kendaraannya dalam keadaan yang jelek kepada konsumen kredit. Hal ini berimbas kepada kelancaran kreditnya karena kendaraan tersebut tidak dapat beroperasi atau tidak dapat digunakan. Dari 12 dealer mobil bekas yang sudah PKS dengan Adira, teridentifikasi 3 dealer bermasalah dengan nilai $25 \%$.

Masing-masing dari faktor-faktor tersebut kemudian disusun kedalam matriks EFE, serta ditentukan bobot dan ratingnya agar didapatkan kondisi perusahaan secara eksternal dengan indikator total dari jumlah skor terbobot yang terlihat pada tabel 5 berikut.

\begin{tabular}{|c|c|c|c|}
\hline \multicolumn{4}{|c|}{ Tabel 5. Hasil Matrik EFE } \\
\hline KEY EXTERNAL FACTOR & \multirow{2}{*}{ BOBOT } & \multirow{2}{*}{ RATING } & \multirow{2}{*}{$\begin{array}{c}\text { SKOR } \\
\text { TERBOBOT }\end{array}$} \\
\hline OPPORTUNITY & & & \\
\hline $\begin{array}{l}\text { Jumlah merk mobil dan dealer mobil hampir } \\
\text { merata }\end{array}$ & 0.15 & 4 & 0.60 \\
\hline Dealer mobil bekas yg belum tergarap & 0.10 & 3 & 0.30 \\
\hline $\begin{array}{l}\text { Permintaan masyarakat yg cukup tinggi } \\
\text { terhadap kredit kendaraan }\end{array}$ & 0.15 & 4 & 0.60 \\
\hline $\begin{array}{l}\text { Pertumbuhan penduduk dan sector niaga yang } \\
\text { cukup tinggi }\end{array}$ & 0.10 & 3 & 0.30 \\
\hline $\begin{array}{l}\text { Pelanggan yang terdiri hampir seluruh lapisan } \\
\text { masyarakat }\end{array}$ & 0.10 & 4 & 0.40 \\
\hline \multicolumn{4}{|l|}{ Threat } \\
\hline Harga komoditi pertanian belum stabil & 0.15 & 3 & 0.45 \\
\hline Adanya peraturan tentang DP (Down payment) & 0.05 & 2 & 0.10 \\
\hline
\end{tabular}

\begin{tabular}{|l|c|c|c|}
\hline Asumsi DP rendah menguntungkan masyarakat & 0.05 & 3 & 0.15 \\
\hline $\begin{array}{l}\text { Afiliasi Bank dengan bunga murah menjadi } \\
\text { ancaman }\end{array}$ & 0.10 & 3 & 0.30 \\
\hline Dealer nakal & 0.05 & 1 & 0.05 \\
\hline Total & 1 & & 3.25 \\
\hline
\end{tabular}

Berdasarkan tabel matriks EFE, peluang utama bagi PT Adira Multifinance Cabang Baturaja adalah jumlah merk mobil, dealer mobil hampir merata dan permintaan masyarakat yang cukup tinggi terhadap kredit kendaraan, dengan skor sebesar 0.15. Meskipun begitu dealer mobil bekas yang belum tergarap, pelanggan yang terdiri dari hampir seluruh lapisan masyarakat dan pertumbuhan penduduk pada sektor niaga cukup tinggi tidak kalah penting, ketiga faktor ini memiliki nilai skor yang cukup tinggi, masing masing yakni 0.1 .

Harga komoditi pertanian belum stabil, merupakan ancaman utama Adira Finance Cabang Baturaja dengan skor 0.15. berikutnya afiliasi Bank dengan bunga murah menjadi ancaman kedua dengan skor 0.10 , adanya peraturan tentang down payment, asumsi DP rendah menguntungkan masyarakat dan adanya dealer mobil yang nakal, merupakan 3 ancaman utama yang dihadapi oleh PT Adira Multifinance Cabang Baruraja. Ketiga faktor ini mempengaruhi lingkungan eksternal PT Adira Multifinance Cabang Baruraja masingmasing sebesar $5 \%$.

Secara keseluruhan, total nilai skor terbobot dari lima peluang dan lima ancaman pada matriks EFE adalah sebesar 3.25 atau berada di atas nilai rata-rata yaitu 2,50. Berdasarkan total nilai terbobot tersebut dapat disimpulkan bahwa PT Adira Multifinance Cabang Baturaja mampu merespon lingkungan eksternal perusahaan dengan memanfaatkan peluang yang dimiliki perusahaan untuk menghadapi ancaman.

\section{Analisis faktor kunci internal}

Faktor-faktor yang terdapat dalam analisis ini digunakan untuk menyusun matriks IFE, yang terdiri dari kekuatan (strengt) dan kelemahan (weakness) yang dimiliki perusahaan, setelah dilakukan proses identifikasi maka kekuatan dan kelemahan yang dimikili oleh PT. Adira 
Multifinance Cabang Baturaja adalah:

\section{Kekuatan}

1. Memiliki market presence yang signifikan (merk, pangsa pasar dan produk )

Adira sebagai salah satu perusahaan multi finance terkemuka di Indonesia, telah membuktikan posisinya dengan beberapa penghargaan yang diterima dari tahun 2006 sampai sekarang, diantaranya : Investor Award 2011 kategori top executif of multifinance company, Investor Award 2011 kategori penerbit obligasi terbaik, Indonesia most admired CEO 2011, Indonesia customer satisfaction award (ICSA) 2011-2012, Infobank multifinance award 2011 kategori golden trophy award, Indonesia best brand award 2011-2012, Indonesia human capital study award (IHCS) 2011-2012 the best all criteria, Service quality award 2011, The best public company of the year 2011, Good corporate governance award 2012, Top brand 2012, Asian banker award 2012; the international execellent in retail financial service award 2012,Indonesia multifinance award 2013; the best multifinance Indonesia for asset > Rp 5 Triliun.

Keunggulan PT Adira multifinance tidak lain juga didukung oleh multi produk automotive, diantaranya syariah dan SGU, masing-masing keunggulan produk ini adalah, DP yang hanya $20 \%$ dari harga kendaraan untuk syariah dan untuk produk SGU yang diperuntukkan bagi pengguna ekonomis (truk, colt diesel dll.) DP yang ditawarkan adalah sebesar 15\% (sumber: www.adira.co.id).

2. Network yang luas dalam bentuk kantor Cabang dan kantor pembantu

Adira finance Cabang Baturaja mempunyai 6 kantor Cabang pembantu yang tersebar di Oku Timur; Martapura, dan Blitang, Oku Selatan; Muaradua, Muara enim, Lahat, dan Pagar Alam. Banyaknya kantor-kantor cabang dan kantor cabang pembantu yang dibuka, sehingga meluaskan daerah pemasaran.

3. Cover area luas

Cover area yang luas merupakan keunggulan
PT. Adira Multifinance Cabang Baturaja lainnya, wilayah cakupan operasional perusahaan ini tidak hanya berada pada kabupaten Baturaja saja, tetapi juga termasuk di kabupaten-kabupaten disekitarnya, seperti Lahat, Muara Enim, dll.

4. Penerapan teknologi untuk dealer mobil bekas (ad1gate, DMS)

Dalam proses kredit kendaraan pemberian PO (purchasing order) biasanya merupakan proses yang rumit dan memakan waktu yang lama karena harus diantarkan dari kantor Cabang. Namun dengan adanya fasilitas ad1gate ini, proses pemberian PO berjalan lebih cepat, bisa langsung diakses dari dealer. Begitu juga dengan kondisi manajemen dealer mobil bekas yang cenderung masih manual dan tradisional, dengan adanya Dealer Management System, akan membantu dealer dalam mengembangkan bisnis lebih rapi.

5. MOU dengan semua merk

Pasar mobil di Indonesia, khususnya daerah Baturaja dipenuhi oleh merk-merk yang berasal dari Jepang dan Korea, sampai saat ini terdapat 9 merk mobil yang berada pasar mobil bekas di Baturaja, dan PT Adira Multifinance Cabang Baturaja telah melakukan kerjasama dengan semua merek tersebut.

\section{Kelemahan}

1. Kebijakan bagi dealer untuk menjual mobil bekas saja

Dalam menjalankan bisnisnya PT. Adira Multifinance Cabang Baturaja mempunyai kebijakan tertentu kepada dealer, seperti kebijakan untuk hanya menjual mobil bekas saja, namun keadaan di lapangan mengindikasikan bahwa terdapat dealer-dealer mobil bekas yang juga menjual dealer baru. Sehingga ini menyebabkan satu dealer tersebut memiliki kerja sama dengan leasing lain.

2. Man Power kecil

Tersebar dan luasnya wilayah cover Adira di lima kabupaten, sementara jumlah tenaga 
lapangan atau man power (MP) dalam bisnis kredit kendaraan mobil merupakan faktor yang sangat krusial bagi perusahaan, mengingat hampir seluruh kegiatan bisnis perusahaan berapa di luar kantor atau lapangan, yang saat ini hanya berjumlah 10 orang. Karena itulah jumlah MP yang kecil merupakan salah satu kekurangan dari PT Adira Multifinance Cabangbaturaja.

3. Proses SL luar kota lama

Seperti yang telah dijelaskan sebelumnya bahwa meskipun berpusat di Baturaja, namun kegiatan bisnis PT. Adira tidak hanya di Baturaja saja, tetapi juga pada kebupatenkabupaten disekitarnya, Sering kali pengajuan kendaraan berasal dari luar kota, dan proses standar layanan (SL) luar kota yang lama, merupakan salah satu kelemahan PT. Adira Multifinance Cabang Baturaja, dan hal ini tergambar dari data SLS luar kota order to PO (Purchase Order) yang tidak ada sampai $100 \%$ dari target. dimana acuannya adalah 8 jam.

4. $\mathrm{L} / \mathrm{R}$

Secara umum pendapatan dari industri kredit kendaraan berasal dari selisih bunga yang didapat yang diberikan kepada pemohon kredit dan bunga yang dibebankan bank. Demikian juga dengan PT. Adira Multifinance Cabang Baturaja, lending rate (L/R) yang diberikan bank sangat tinggi, sehingga margin keuntungannya sangat kecil, dan akan sangat beresiko jika dilakukan penurunan tingkat bunga kredit kepada konsumen.

5. Partial early termination

Pencairan permohonan kredit kendaraan pada PT. Adira Multifinance Cabang Baturaja memakan waktu yang cukup lama, yaitu 3 hari, sementara pada perusahaan lain atau pesaing, pencairan bisa dilakukan dalam waktu 2 hari atau lebih cepat.

Masing-masing dari faktor-faktor tersebut kemudian disusun ke dalam matriks IFE, serta ditentukan bobot dan ratingnya agar didapatkan kondisi perusahaan secara eksternal dengan indikator total dari jumlah skor terbobot yang terlihat pada tabel 6 berikut.

\begin{tabular}{|c|c|c|c|}
\hline \multicolumn{4}{|c|}{ Tabel 6. Hasil Matrik IFE } \\
\hline KEY INTERNAL FACTOR & \multirow{2}{*}{ ВОВОт } & \multirow{2}{*}{ RATING } & \multirow{2}{*}{$\begin{array}{c}\text { SKOR } \\
\text { TERBOBOT }\end{array}$} \\
\hline STRONG & & & \\
\hline Memiliki market presence yang signifikan & 0.15 & 4 & 0.60 \\
\hline $\begin{array}{l}\text { Network luas dalam bentuk kantor Cabangdan } \\
\text { kantor pembantu }\end{array}$ & 0.15 & 4 & 0.60 \\
\hline Cover area luas & 0.10 & 4 & 0.40 \\
\hline $\begin{array}{l}\text { Penerapan teknologi untuk dealer mobil bekas } \\
\text { (ad1gate,DMS) }\end{array}$ & 0.10 & 3 & 0.30 \\
\hline MOU dengan semua merk mobil & 0.10 & 3 & 0.30 \\
\hline \multicolumn{4}{|l|}{ Weakness } \\
\hline $\begin{array}{l}\text { Kebijakan bagi dealer untuk menjual mobil } \\
\text { bekas saja }\end{array}$ & 0.05 & 3 & 0.15 \\
\hline Man Power kecil & 0.10 & 2 & 0.20 \\
\hline Proses SL luar kota lama & 0.10 & 2 & 0.20 \\
\hline$L / R$ & 0.10 & 2 & 0.20 \\
\hline Pembayaran produk adira lama & 0.05 & 1 & 0.05 \\
\hline Total & 1 & & 3.00 \\
\hline \multicolumn{4}{|c|}{ Sumber : Data primer diolah } \\
\hline
\end{tabular}

Penetapan nilai peringkat pada matrik internal faktor evaluasi (IFE) dilakukan dengan mempertimbangkan tingkat kepentingan dari masingmasing variable dalam faktor tersebut. Sedangkan pemberian bobot didasarkan pada besarnya pengaruh dari variable dalam upaya mendorong perkembangan usaha PT. Adira Finance sesuai dengan hasil pembobotan jawaban dari pakar 1 yang merupakan pimpinnan PT.Adira Finance

Berdasarkan matriks IFE menunjukkan bahwa faktor kekuatan PT Adira Multifinance Cabang Baturaja memiliki skor tertinggi pada memiliki market presesence yang signifikan, network luas dengan kantor cabang dan kantor pembantu senilai 0.15 , sementara cover area yang luas, penerapan teknologi untuk dealer mobil bekas dan MOU dengan semua merk kendaraan mobil, dengan skor pada masing masing faktor sebesar 0.10 atau $10 \%$.

Kelemahan utama yang dimiliki oleh PT Adira Multifinance Cabang Baruraja adalah Man power kecil, proses Service level dan L/R dengan skor 0.10 . Kelemahan perusahaan lainnya adalah kebijakan dealer bekas hanya menjual mobil bekas saja dan pembayaran produk Adira lama yaitu masing-masing 0.05 .

Secara keseluruhan, total nilai skor terbobot dari enam kekuatan dan enam kelemahan pada matriks IFE adalah sebesar 3.00. Dengan demikian, kondisi internal perusahaan hanya bera- 
da sedikit diatas nilai rata-rata yaitu 2,50. Berdasarkan total nilai terbobot tersebut dapat disimpulkan bahwa PT Adira Multifinance Cabang Baruraja berada pada posisi cukup kuat dalam memanfaatkan kekuatan yang dimiliki untuk mengatasi kelemahan yang ada.

\section{Tahap Mencocokan Data (The Matching Stage) Matrix TOWS}

Matriks TOWS disusun berdasarkan hasil identifikasi faktor internal dan faktor eksternal perusahaan, meliputi kekuatan dan kelemahan yang dimiliki perusahaan serta peluang dan ancaman yang dihadapi oleh perusahaan. Pemaduan faktor internal dan eksternal perusahaan dalam matriks TOWS akan menghasilkan beberapa alternatif strategi yang dapat digunakan oleh perusahaan.

Matriks TOWS dapat menghasilkan empat set kemungkinan alternatif strategi yaitu strategi S-O yang berasal dari pencocokan antara kekuatan dan peluang perusahaan, strategi S-T yang berasal dari pencocokan kekuatan dan ancaman yang dihadapi perusahaan, strategi W-O yang berasal dari kelemahan perusahaan dan peluangpeluang yang ada dan strategi W-T yang berasal dari kelemahan perusahaan dan ancaman yang dihadapi. Untuk lebih jelasnya matrik TOWS dapat dilihat pada tabel 7 .

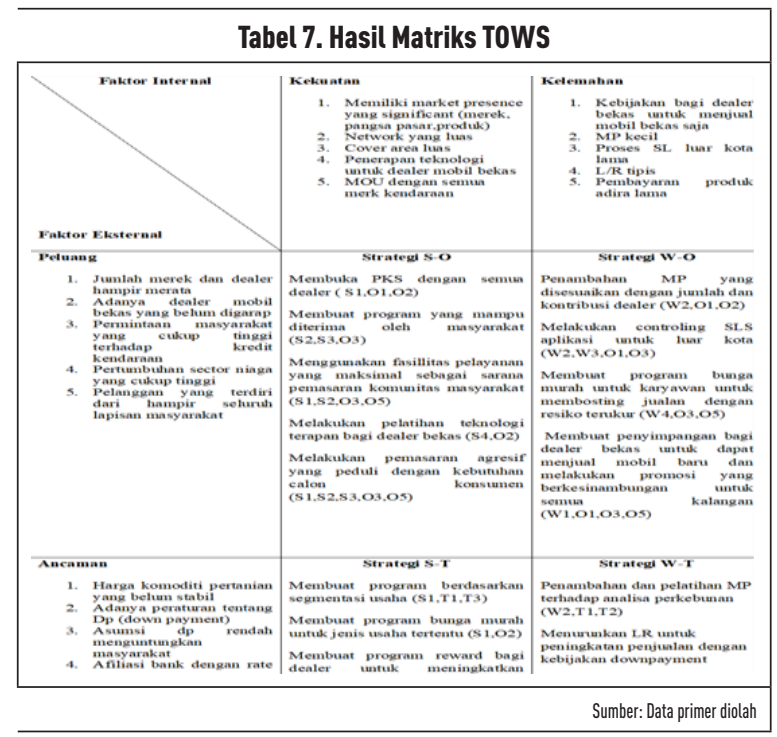

Analisis SWOT memberikan gambaran strategi secara mendetail dari Adira Finance Cabang Baturaja. Dengan adanya analisis menggunakan matriks SWOT, Adira Finance Cabang Baturaja dapat melihat rincian strategi yang dapat diaplikasikan untuk meningkatkan kinerja perusahaan.

\section{Analisis IE Matrix}

Matriks IE (internal external) merupakan matriks portofolio yang memposisikan perusahaan dalam tampilan sembilan sel. Posisi suatu perusahaan dalam matriks IE ditentukan dari matriks EFE dan matriks IFE. Hasil skor total dari IFE Matrix berada pada sumbu $\mathrm{X}$ dan skor total dari EFE Matrix berada pada sumbu Y. Dari hasil analisis EFE dan analisis IFE, matriks EFE Adira Finane Cabang Baturaja memiliki skor total 3,25 sementara matriks IFE Telkom Malang memiliki skor total 3,00. Posisi Adira Finance Baturaja dalam matriks IE dapat digambarkan sebagai berikut :

Tabel 8. MATRIX IE ADIRA FINANCE SCORE TOTAL BOBOT IFE

\begin{tabular}{|c|c|c|c|c|}
\hline & & Kuat $(3.0-4.0)$ & Sedang (2.0-2.99) & $\operatorname{Lemah}(1,0-1,99)$ \\
\hline \multirow{4}{*}{$\begin{array}{c}\text { SCORE TOTAL } \\
\text { BOBOT EFE }\end{array}$} & & & & \\
\hline & Tinggi (3.0-4.0) & I & II & III \\
\hline & Sedang (2.0-2.99) & IV & $\mathrm{v}$ & VI \\
\hline & Rendah $(1,0-1,99)$ & VII & VIII & $\mathrm{IX}$ \\
\hline
\end{tabular}

Menurut matriks IE, maka posisi Adira Finance Cabang Baturaja berada dalam kuadran I. Posisi ini mengindikasikan Adira Finance Cabang Baturaja dalam posisi tumbuh dan membangun (growth and built). Strategi yang bisa diterapkan antara lain strategi yang intensif (penetrasi pasar, pengembangan pasar, dan pengembangan produk) atau integratif (integrasi ke belakang, integrasi ke depan, dan integrasi horizontal) bisa menjadi pilihan yang paling tepat. Namun strategi yang paling tepat untuk kondisi Adira Finance Cabang Baturaja saat ini adalah strategi intensif yang meliputi penetrasi pasar, pengembangan pasar, dan pengembangan produk. Strategi integratif kurang tepat untuk diaplikasikan karena strategi ini memungkinkan sebuah usaha untuk memperoleh kendali atas distributor, pemasok, dan/atau pesaing. Saat ini, Adira Finance Cabang Baturaja belum memiliki kapasitas untuk menjadi pemegang kendali bagi distributor, pemasok, dan/atau pesaing. 


\section{Tahap Keputusan (The Decision Stage)}

Tahap akhir dari analisis formulasi strategi adalah tahap pengambilan keputusan yaitu pemilihan strategi terbaik menurut prioritas dari 3 alternatif strategi yang ada, karena itu keputusan diambil dengan mengevaluasi kembali secara obyektif dengan menggunakan Quantitative Strategic Planning Matrix.

\begin{tabular}{|c|c|c|c|c|c|c|c|c|}
\hline \multicolumn{9}{|c|}{ Tabel 4.5. Matriks QSPM } \\
\hline \multirow{3}{*}{\multicolumn{2}{|c|}{ Faktor Utama }} & \multirow{3}{*}{$\begin{array}{l}\text { Weight } \\
\text { (Bobot) }\end{array}$} & \multicolumn{6}{|c|}{ Alternatif Strategi } \\
\hline & & & \multicolumn{2}{|c|}{$\begin{array}{c}\text { Market } \\
\text { Penetration }\end{array}$} & \multicolumn{2}{|c|}{$\begin{array}{c}\text { Market } \\
\text { Development }\end{array}$} & \multicolumn{2}{|c|}{$\begin{array}{c}\text { Product } \\
\text { Development }\end{array}$} \\
\hline & & & AS & TAS & AS & TAS & AS & TAS \\
\hline Peluang & & & & & & & & \\
\hline 1. & $\begin{array}{l}\text { Jumlah merek mobil dan dealer } \\
\text { mobil hampir merata }\end{array}$ & 0.15 & 4 & 0.60 & 3 & 0.45 & 2 & 0.30 \\
\hline 2. $\mathrm{i}$ & Dealer yang belum digarap & 0.10 & 3 & 0.30 & 4 & 0.40 & 2 & 0.20 \\
\hline 3. & $\begin{array}{l}\text { Permintaan masyarakat yang cukup } \\
\text { tinggi terhadap kredit kendaraan }\end{array}$ & 0.15 & 4 & 0.60 & 3 & 0.45 & 2 & 0.30 \\
\hline 4. & $\begin{array}{l}\text { Pertumbuhana pendudukk dan sector } \\
\text { niaga yang cukup tinggi }\end{array}$ & 0.10 & 4 & 0.40 & 3 & 0.30 & - & - \\
\hline 5. & $\begin{array}{l}\text { Pelangganan yang terdirir dari hampir } \\
\text { selurubl lapisan masyarakat }\end{array}$ & 0.10 & 4 & 0.40 & 3 & 0.30 & - & - \\
\hline \multicolumn{2}{|c|}{ Ancaman } & & & & & & & \\
\hline 1. & $\begin{array}{l}\text { Harga komoditi pertanian belum } \\
\text { stabil }\end{array}$ & 0.15 & 2 & 0.30 & 3 & 0.45 & 4 & 0.60 \\
\hline 2. & $\begin{array}{l}\text { Adanya peraturan tentang } \mathrm{Dp} \text { (down } \\
\text { payment) }\end{array}$ & 0.05 & 4 & 0.20 & 3 & 0.15 & - & - \\
\hline 3. & $\begin{array}{l}\text { Asumsi masyarakat yang } \\
\text { menganggap DP rendah } \\
\text { menenutunumekan }\end{array}$ & 0.05 & - & - & - & - & - & - \\
\hline & $\begin{array}{l}\text { Afiliasib bank dengan bunga rendah } \\
\text { menjadi ancaman }\end{array}$ & 0.10 & 4 & 0.40 & 3 & 0.30 & 2 & 0.20 \\
\hline 5. $\mathrm{i}$ & Dealer nakal & 0.05 & . & . & . & . & . & \\
\hline \multicolumn{2}{|l|}{ Total } & 1 & & & & & & \\
\hline \multicolumn{9}{|c|}{ Sumber: Data primer diolah } \\
\hline
\end{tabular}

Berdasarkan hasil analisis matriks QSPM diatas, Maka didapat hasil sebagai berikut :

1. Untuk alternatif strategi pertama yaitu penetrasi pasar (market penetration) dengan peningkatan pangsa pasar untuk produk atau jasa yang ada di pasar, memiliki nilai TAS sebesar 6.45

2. Alternatif strategi kedua yaitu pengembangan pasar (market development) dengan pengenalan produk atau jasa ke wilayah baru memiliki nilai TAS sebesar 5.50

3. Alternatif strategi ketiga yaitu pengembangan produk (product development) dengan peningkatan penjualan dengan memperbaiki atau memodifikasi produk atau jasa, memiliki nilai TAS sebesar 3.40

Berdasarkan alternatif strategi diatas maka didapatlah bahwa strategi yang paling prioritas untuk dilakukan oleh PT. Adira Multifinance Cabang Baturaja adalah, dengan nilai TAS tertinggi sebesar 6.45 .

\section{SIMPULAN}

Penelitian ini bertujuan untuk mengetahui konsidi eksternal PT. Adira Multifinance Cabang Baturaja yang berupa peluang-peluang yang ada dan hal-hal yang mengancam perusahan, serta mengetahui kondisi internal perusahaan yang yang terdiri dari kekuatan dan kelemahan yang dimiliki perusahaan. Kedua faktor tersebutlah (eksternal dan internal) yang kemudian menjadi landasan dalam perumusan strategi PT. Adira Multifinance Cabang Baturaja.

Hasil penelitian menemukan bahwa dari hasil analisis EFE dan IFE, matriks EFE Adira Finance Cabang Baturaja memiliki skor total 3,25 sementara matriks IFE Cabang Baturaja memiliki skor total 3,00. Posisi dalam kuadran matriks IE ditentukan dari skor total matriks IFE sebagai sumbu $\mathrm{X}$ dan skor total matriks EFE sebagai sumbu Y.

Dari hasil analisis ini, maka posisi Adira Finance Cabang Baturaja berada dalam kuadran I. Posisi ini mengindikasikan Adira Finance Cabang Baturaja dalam posisi tumbuh dan membangun (grow and built). Strategi yang bisa diterapkan antara lain strategi yang intensif (market penetration, market development, dan product development) atau integratif(integrasi ke belakang, integrasi ke depan, dan integrasi horizontal).

Berdasarkan hasil analisa matriks QSPM, Adira Finance Cabang Baturaja dapat menggunakan strategi market penetration. Strategi ini adalah strategi yang dirasa paling tepat untuk dilakukan oleh Adira Finance Cabang Baturaja dalam menghadapi perubahan lingkungan yang terjadi.

\section{PENGHARGAAN}

Puji syukur saya sampaikan kehadirat Allah SWT, yang telah memberikan rahmat dan kehendak-Nya sehingga terselesaikan penelitian ini. Juga, rasa terima kasih ini juga saya sampaikan kepada PT Adira Dinamika Multifinance, kepada direksi, kepala dealer dan konsumen yang telah memberi masukan dan mengisi daftar pertanyaan yang saya berikan sehingga terwujudlah hasil penelitian ini.

\section{DAFTAR PUSTAKA}

Cravens, David W. (1996). Pemasaran Strategis, 
Jilid 1. Jakarta: Penerbit Erlangga.

David et. All.(2009). The Quantitative Strategic Planning Matrix (Qspm) Applied To A Retail Computer Store. The Coastal Business Journal, Vol 8, 1.

David, F. (2011). Strategic Management Concepts and Cases. Upper Saddle River, NJ: PrenticeHall Publishing Company.

David, F. R. (1998). Manajemen Strategis : Konsep, Edisi Tujuh, Terjemahan oleh Alexander Sindoro, 2002. Jakarta: Prenhallindo.

Delbahari, \& Hamidi. 2011. Formulating a Strategy for a University Using SWOT Technique: A Case Study. Australian Journal of Basic and Applied Sciences, 5(12): 264-276, ISSN 19918178.

Glueck, W.F., \& Jauch, L.R. (1999). Manajemen Strategi dan Kebijakan Perusahaan. Terjemahan oleh Murad \& A.R. Henry Sitanggang. Jakarta: Erlangga.

Hariadi, B. (2005). Strategi Manajemen. Malang : Bayumedia.

Hashemi et.all. (2011). Formulating And Choosing Strategies Using Swot Analysis And Qspm Matrix: A Case Study Of Hamadan Glass Company. Proceedings of the $41^{\text {st }}$ International Conference on Computers \& Industrial Engineering.

Hax, A., \& Nicholas S.M. (1991). The Strategy Concept And Process : A Prafgamatic Approach, Third Edition. New Jersey: Prentice Hall Inc Englewood Cliffs.

Hayun, A. (2005). Evaluasi dan Perumusan Strategi Telkom Flexi Dengan Menggunakan Model David. INASEA, Vol. 6, no.2.

Hunger,\& Wheelen. (2000). Strategic Management \& Business Policy, 8th edition. Upper Saddle River, New Jersey: Prentice Hall.

Kotler, P (2000), Manajemen Pemasaran (edisi millenium) Jilid 2. Jakarta: penerbit Prenhallindo.

Kotler, P. (2003). Marketing Management : $11^{\text {th }}$ ed. Upper Saddle River, New Jersey: Pearson Education, Inc.

Marzuki. (2005). Metodologi Riset. Yogyakarta: BPFE Universitas Islam Indonesia.

Nejad, P., \& Sojaee. 2011. Applying Topsis
And Qspm Methods In Framework Swot Model: Case Study Of The Iran's Stock Market. Australian Journal of Business and Management Research, Vol.1, No.5 ,93-103.

Pearce, J. A., \& Robinson R.B. (1996). Manajemen Strategik, Jilid 1. Terjemahan oleh Agus Maulana, 1997. Jakarta: Binarupa Aksara.

Pearce, J. A., \& Robinson, R.B. (2004). Strategic Management: Formulation, Implementation and Control, $10^{\text {th }}$ Edition. New York: Mcgraw Hill Higher Education.

Porter, M.E. (1994). Keunggulan Bersaing : Menciptakan dan Mempertahankan Kinerja Unggul, Edisi Bahasa Indonesia. Jakarta: Binarupa Aksara.

Rangkuti, F. (2002). Analisis SWOT Teknik Membedah Kasus Bisnis. Jakarta: PT. Gramedia Pustaka Utama.

Saleh, \& Sukaris. (2008). Analisis matriks SPACE Dalam Perumusan Strategi Bisnis Pada Koperasi Karyawan PLN Sektor Gresik. Jurnal Logos Vol.6 no.1 Juli, 98-111.

Sule, E.T., \& Saefullah, K. (2005). Pengantar Manajemen. Jakarta: Kencana.

Suwarsono, M. (2003). Manajemen Strategi : Konsep dan Kasus. Yogyakarta: UPP AMP YKPN.

Umar, H. (2003). Strategic Management in Action. Jakarta: Gramedia Pustaka Utama.

Wheelen, T. L. \& Hungger, J.D. (1996). Manajemen Strategis. Terjemahan oleh Agung Julianto, 2001. Yogyakarta: Andi. 